\title{
Bridging theory-to-practice gaps in a long-term ventilated unit during the COVID-19 pandemic
}

\author{
Jose Arnold Tariga* \\ Amana Healthcare, United Arab Emirates
}

Received: February 28, 2021

Accepted: May 16, 2021

Online Published: May 26, 2021

DOI: $10.5430 /$ jnep.v11n9p61

URL: https://doi.org/10.5430/jnep.v11n9p61

\begin{abstract}
Background and objective: COVID-19 had greatly impacted nurse-patient ratios worldwide, forcing hospitals to hire new nurses with minimal experience or without specialized skills. To ensure clinical competence, the author developed the Long Term Critical Care Transition Modules and conducted this study to assess its effectiveness.

Methods: Three learning modules were developed and data were collected using a researcher-made questionnaire and competency checklist. Results were analyzed using descriptive statistics and paired $t$-test to evaluate if there was a significant improvement in the skills and competence levels before and after being subjected to the modules.

Results: Demographic profiles indicated that majority of the nurses were in their early career. A significant improvement of competency levels among nurses post-module attendance was also noted $(p<.05)$.

Conclusions: The transition modules can be an effective methodology in upskilling nurses with minimal or without prior experience in long-term care, within a short period of time.
\end{abstract}

Key Words: COVID-19 pandemic, Long-term care, Transition modules, Bridging competency gaps, Clinical competence, Nurses

\section{INTRODUCTION}

Since the announcement of COVID-19 as a pandemic of international concern in January 2020 by the World Health Organization (WHO), the virus had infected millions of people to date across the globe. ${ }^{[1]}$ This led to the surge of patient admissions in various healthcare facilities, both acute and long-term care settings, which further generated a negative impact on the already problematic nurse-patient ratio.

Adequate staffing had always been one of the prerequisites of ensuring secure working conditions for nurses and delivery of safe patient care in the clinical area. With the progression of the pandemic, many healthcare facilities across the world faced the issue of staffing shortage, particularly with nurses. ${ }^{[2]}$ Nurses play a vital role in the provision of care in various healthcare settings, be it hospitals or long-term care facilities, and their role and value were further highlighted during this pandemic. ${ }^{[3]}$

In the State of the World's Nursing report released by WHO, there was an estimate of 5.9 million nursing shortages on a global scale, which was further aggravated by the strain brought about by COVID-19 to global health systems. ${ }^{[4]}$ The International Council of Nurses (ICN) had also forecasted an international scarcity of greater than 10 million nurses by the year 2030 without accounting for the undesirable effects of the COVID-19 pandemic. ${ }^{[5,6]}$ The foregoing imbalance in nurse-patient ratios was amplified during the peak of the pandemic and can be attributed to a myriad of factors, including but not limited to exposures in the clinical area,

*Correspondence: Jose Arnold Tariga; Email: jtariga@ amanahealthcare.com; Address: Amana Healthcare, United Arab Emirates. 
sickness, burnout, and the need to look after family members at home. ${ }^{[2,3]}$

\subsection{Impact of nursing shortage in long-term care set- tings during the pandemic}

Long-term care facilities were particularly susceptible to the negative impact brought about by the COVID-19 crisis. Patients and residents of long-term care in-patient hospitals were mostly composed of the elderly and vulnerable population with numerous underlying conditions and comorbidities. ${ }^{[7,8]}$ The majority of long-term care and rehabilitation facilities are home to residents with complex needs receiving long-term mechanical ventilation and full assistance in terms of activities of daily living. Hence, an insufficient supply of nurses makes the crisis more acute in long-term care settings.

\subsection{Mitigating nursing shortage}

Healthcare organizations worldwide were forced to adopt creative strategies to ensure maintenance of optimal staffing, particularly in high-risk, critical care, and long-term care areas. Many organizations responded to the challenge through a dial-up and dial-down mechanism wherein nurses from non-critical areas were moved or reassigned to critical care and long-term care units. ${ }^{[9,10]}$ Other contingency capacity strategies employed by health care facilities were adjusting the staffing schedules, rotating nurses to positions that support patient care activities, and hiring additional staff to increase the workforce. ${ }^{[2,9,10]}$ As there was already a shortage of specialized-trained nurses, some organizations were enforced to hire new nurses even those with very minimal experience in providing specialized services such as caring for critically ill or mechanically ventilated patients in longterm care units. This then imposed the necessity to align the nurses' clinical skills and competencies to make certain that they deliver safe patient care.

\subsection{Building competencies and upskilling}

Repurposing and reassigning nurses to improve workforce availability calls for innovative approaches in providing accelerated training to upskill and build the needed competencies. $^{[10]}$ It must be considered that certain specialized services such as long-term care ventilated units require key clinical skills as patients in these areas will vary in terms of case acuity and complexity levels. ${ }^{[11,12]}$ The continued progression of COVID-19 had highlighted the necessity of having effective and well-structured educational and training strategies to enhance the competencies of inexperienced nurses who are exposed to critical care areas within a very short span of time. Therefore, during this pandemic, nurses working in long-term care ventilated units must receive focused and well-developed education and training based on the needs of patients and the organization. ${ }^{[11,13]}$

\subsection{Research aim}

With the aim of addressing staffing deficit and improving nursing workforce availability during the pandemic crisis, the management of Amana Healthcare's Adults Facility intensified nurse recruitment. Amana Healthcare, a Mubadala Health Partner, is a provider of inpatient long-term care in the Middle East and is accredited by international accrediting bodies such as the Joint Commission International (JCI) and Commission on Accreditation of Rehabilitation Facilities (CARF). Amana Healthcare's long-term care program for adults caters for medically complex patients on long-term mechanical ventilation and those with chronic comorbidities needing assistance with all aspects of care. ${ }^{[14]}$ Among the new hires were nurses who did not have recent experience or with very minimal exposure in critical care, long-term care, and rehabilitation.

To manage the theory and practice gaps, the author in coordination with the multidisciplinary team developed three transition modules focused on the foundations of long-term care and nurse-led therapy, assessment and management of mechanically ventilated patients, and assessment and management of deteriorating adults. The modules aimed at providing nurses with the core knowledge and competencies to manage ventilated long-term care patients, thereby ensuring patient safety.

This inquiry was then conducted to evaluate the effectiveness and efficacy of the transition modules. The author aimed to outline the nurses' demographic variables such as age, educational qualification, and length of clinical experience in years; evaluate and describe their competency levels pre and post-module delivery, and assess the correlation between competence levels and the demographic profiles.

\subsection{Conceptual framework}

Donabedian's framework (see Figure 1) was utilized in developing a structured process to facilitate a safe transition and adaptation of nurses, with the main aim of enhancing their clinical competencies, thereby improving the quality of care. ${ }^{[9,15,16]}$

In terms of structure, core competencies and gaps were identified and analyzed. And based on learning needs, the transition modules were developed. As to the process, modules were provided to the participants followed by competency validation and remediation. The expected outcome was to improve the nursing competency levels following module exposure. 
-Identification of Core Competencies

- Competency Gap Analysis

-Module Development based on Core Competencies

-Module Delivery

- Competency Remediation

- Competency Validation

Outcome

-Improved Nursing Competency Levels

Figure 1. Conceptual Framework of the Study

\subsection{Development of transition modules}

The transition modules were developed to enhance the knowledge and competencies of newly hired nurses without prior experience in handling ventilated patients in long-term care settings. The author, who was the education coordinator at the time the study was conducted, brainstormed with a group of experts to capture insights on what competencies were considered vital to facilitate rapid clinical upskilling. The team included the director of clinical operations, clinical coordinator, lead therapist, lead physician, senior respiratory therapist, and two senior staff nurses. The author also sent out a training needs assessment (TNA) survey that examined the nurses' perceived important topics that will help them adapt to the new area of assignment. Following the brainstorming sessions and TNA survey, three main modules were developed as shown in Table 1.

Educational materials were developed and contents were reviewed by the experts. Materials were also piloted with a group of nurses. Feedbacks were collated and amendments were done as per recommendations before the final educational materials were delivered to the participants.

Table 1. Transition Modules and Core Topics

\begin{tabular}{|c|c|}
\hline Modules & Core Topics \\
\hline $\begin{array}{l}\text { Module 1: Foundations in long-term care and } \\
\text { nurse led-therapy }\end{array}$ & $\begin{array}{l}\text { - Difference between acute and long-term care } \\
\text { - Integrating rehabilitation to nursing care } \\
\text { - Managing pain on patients with varying levels of consciousness } \\
\text { - Sensory integration } \\
\text { - Nutrition in critical illness } \\
\text { - Musculoskeletal integrity } \\
\text { - Spasticity management. }\end{array}$ \\
\hline Module 2: Managing ventilated residents & $\begin{array}{l}\text { - Mechanisms of breathing } \\
\text { - Establishing the need for mechanical ventilation } \\
\text { - Ventilator set-up including calibration, selecting modes and settings } \\
\text { - Monitoring observable and measurable parameters } \\
\text { - Arterial blood gas interpretation } \\
\text { - Discontinuation and liberation or weaning } \\
\text { - Chest therapies }\end{array}$ \\
\hline Module 3: Managing deteriorating adult & $\begin{array}{l}\text { - Primary and secondary assessments } \\
\text { - Identifying early warning signs } \\
\text { - Initial approach to clinical deterioration } \\
\text { - Managing patients with neurological deterioration } \\
\text { - Managing patients with possible shock and sepsis } \\
\text { - Basic electrocardiography (ecg) analysis } \\
\text { - Managing patients with cardiac deterioration }\end{array}$ \\
\hline
\end{tabular}

\section{MATERIALS AND METHODS}

\subsection{Research design}

The author employed a pre-experimental one-group pretestposttest research design. The identified nurses were subjected to pre-test, transition modules, and post-test. This enabled the author to compare the competency levels before and after module exposure.

Published by Sciedu Press

\subsection{Research setting}

The study was conducted in the Amana Healthcare Adults Facility, a 78-bed capacity in-patient long-term hospital located in Al Ain City, Abu Dhabi, UAE. This facility specializes in the care of patients requiring long-term or continuous mechanical ventilation or short-term ventilatory support for patients who can be weaned. The facility also caters to 
patients with complex medical needs such as those with complicated wounds, breathing disorders, chronic lung disease, poly-morbid conditions with complications, and organ failure.

\subsection{Samples and sampling}

The study participants comprised of newly hired nurses employed in Amana Healthcare. The author purposefully chose all nurses who qualified the eligibility criteria. To be eligible, participants must be: (1) a recent joiner or newly hired staff;
(2) currently employed as a full-time employee; and (3) without recent experience in acute critical care, long-term care, and rehabilitation. This generated a total of twelve nurses.

\subsection{Instrumentation}

A competency-based assessment checklist, which was based on the contents of each module, was utilized as the instrument for data gathering. The nurses' competency levels were assessed using a quantified Benner's competency framework $^{[17,18]}$ (see Table 2).

Table 2. Benner's competency levels with rating equivalents

\begin{tabular}{lll}
\hline Levels of Competence & Rating Equivalent & Description \\
\hline Novice & 1 & Lack of knowledge, training or prior experience \\
Advanced Beginner & 2 & Minimal knowledge; unable to perform without support and assistance \\
Competent & 3 & Good knowledge; able to perform on his/her own without support \\
Proficient & 4 & $\begin{array}{l}\text { Very good knowledge; Can solve problems and initiate interventions on his/her own } \\
\text { Expert }\end{array}$ \\
& 5 & $\begin{array}{l}\text { Significant background knowledge; flexible to new situations and able to } \\
\text { confidently mentor others }\end{array}$ \\
\hline
\end{tabular}

\subsection{Data collection}

The author sent a proposal to the senior management and requested to conduct this educational improvement project. After obtaining permission, the author coordinated with the clinical coordinator and human resource department to identify the newly hired nurses without prior experience in handling ventilated long-term care patients. Once identified, participants were then given a pre-test, and then exposed to a 3-day workshop containing the modules. After a week, the participants were then subjected to competency re-evaluation.

\subsection{Ethical approval}

Prior to conducting this project, the author submitted a project proposal to senior management and the director of clinical operations. All procedures were performed in compliance with relevant institutional guidelines and approval was sought from senior management. No ethical approval was needed, as this was an educational improvement project.

\subsection{Data analysis}

Collated data were examined and analyzed utilizing descriptive statistics (percentage, mean, and standard deviations) and inferential statistics (paired T-tests) using Statistical Package for the Social Sciences (SPSS) software.

\section{RESUlts}

\subsection{Demographics}

Twelve newly hired nurses with very minimal or without recent experience in acute critical care, long-term care, and rehabilitation were included in the program and were subjected to the modules. Figure 2 shows the age range, educational qualification, and length of experience.
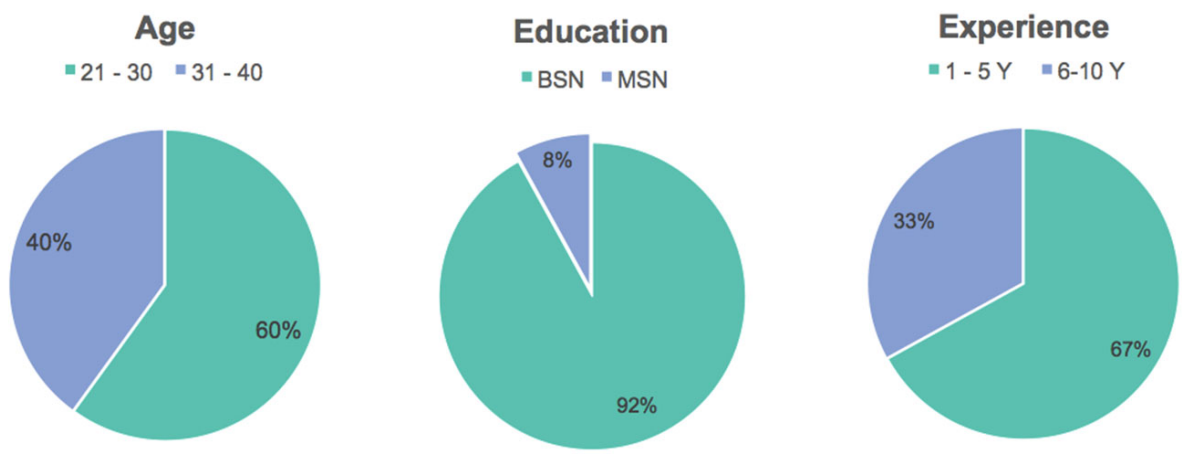

Figure 2. Demographic profile 
The majority or $60 \%$ of the respondents was within the age bracket of 31-40 years and the vast majority (92\%) possessed a bachelor's degree in nursing. Participants were also predominantly new to the profession with $67 \%$ having less than 5 years of clinical experience while only $33 \%$ had been in the profession for six to ten years.

\subsection{Competency levels pre and post transition modules}

As displayed in Table 3, the mean levels of competency among nurses changed prior to and after being subjected to the modules. The average competency before the nurses attended the module was 1.60 (advanced beginner level) while after module exposure, the mean competency levels had increased to 3.31 (competent level). A p-value of $<0.05$ indicated that there was a substantial improvement in competency levels before and after module delivery.

Table 3. Pre and post test competency levels

\begin{tabular}{llll}
\hline $\mathbf{N}=1 \mathbf{1 2}$ & $\begin{array}{l}\text { Mean/ } \\
\text { Average }\end{array}$ & $\begin{array}{l}\text { Standard } \\
\text { Deviation }\end{array}$ & $\begin{array}{l}\text { Standard } \\
\text { Error of Mean }\end{array}$ \\
\hline Pre-test Mean & 1.60 & 0.21 & 0.06 \\
Post-test Mean & 3.31 & 0.21 & 0.06 \\
Difference & -1.71 & 0.18 & 0.05 \\
95\% CI for mean difference: & $p$-value $=$ & $t$-value -32.30 \\
$(-1.83 ;-1.59)$ & & .00 & \\
\hline
\end{tabular}

\subsection{Correlation between demographics and competency levels post-test}

The table below revealed that the demographic variables have little impact on the post-test level of competency, as shown by $p$-values greater than .05 . This finding implied that age, educational level, and length of experience had little effect on the nurses' level of competence.

Table 4. Correlation of Demographic Profile and Post-test Level of Competence

\begin{tabular}{lll}
\hline Demographic Variable & $\begin{array}{l}\text { Correlation with } \\
\text { Post Test Average }\end{array}$ & $\boldsymbol{p}$-value \\
\hline Age & -0.02 & 0.96 \\
Educational Qualification & 0.14 & 0.67 \\
Length of Experience (Years) & -0.29 & 0.36 \\
\hline
\end{tabular}

\section{Discussion}

This study explored the effectiveness of transition modules in ameliorating the competencies of newly hired nurses without prior experience in handling ventilated patients in longterm care settings. Ensuring the availability of a competent workforce, particularly during this pandemic is among the priorities of healthcare facilities to maintain safe and quality care. ${ }^{[10]}$ Nurses should receive relevant training to ascertain that their skills are compatible with the needs of the

Published by Sciedu Press patients. ${ }^{[11,13]}$

This study revealed that the respondents were predominantly in the early to middle career nurse professionals. This result concurred with a research published in another Middle Eastern city, which revealed that the average age of nurses ranges from 20 to 48 years old. ${ }^{[19]}$ The dominance of nurses possessing bachelor's degrees as compared to those with postgraduate degrees can be attributed to the minimum professional requirement for nurses to practice in the UAE. Nurses are allowed to obtain licenses to practice as long as they hold a bachelor's degree in nursing. ${ }^{[20,24]}$ However, although this study revealed that the participants are in their early careers in terms of years of experience, another study with a larger population revealed that the majority of nurses in the UAE had worked for more than 5 years within various clinical settings. ${ }^{[2]}$ This implied that the majority of the newly employed nurses are young nurses having basic training, minimal years of experience, and without specialized training in long-term care.

Another finding that was highlighted in this study was the notable improvement in the competency levels of the participants after being exposed to transition modules. This finding correlated with the study of Levett-Jones et. al., which revealed that clinical competence can be achieved if nurses were adequately trained and prepared using a systematically designed and well-developed training module. ${ }^{[21]}$ Furthermore, Nababan and Saragih who designed an educational module to enhance nursing competence also found out that training modules had helped improve the competence and confidence levels of participants. ${ }^{[22]}$ Another study conducted by KarimiMoonaghi, et. al., also revealed that the respondents who were exposed to learning modules had improved their clinical skills and competencies. ${ }^{[23]}$ Lee and Kim also noted that in order to train nurses, it is important to use a standardized module that includes the necessary competencies for clinical practice. ${ }^{[26]}$ Various clinical training modalities, such as standardized learning modules and simulations, can help enhance nurses' attitudes and efficiency in a variety of clinical settings. ${ }^{[26-28]}$ This indicated that upskilling of nurses with minimal experience during a pandemic crisis can be facilitated through the use of well-structured educational modules.

Furthermore, it was also found out that demographic variables did not impact the post-test level of competence. This result is aligned with the findings of KarimiMoonaghi et al., stating that demographic factors such as gender had very little effect on a nurse's professional competence. ${ }^{[23]}$ Moreover, Benner, as cited by Kim et. al. claimed that the length of experience does not necessarily directly impact the com- 
petence level as it can change once a nurse is shifted to a new area of practice. ${ }^{[25]}$ The study's results, however, contradicted the findings of Keykha et. al., Chan, and Al-Yateem et. al. who found that age, years of service, and higher educational levels all have a large effect on expertise and clinical competence. ${ }^{[24,29,30]}$ According to these researchers, older nurses have usually been in the profession for a long period of time and have extensive clinical experience. Nurses who seek further continuing education gain additional information and experience that increases clinical judgment. ${ }^{[30]}$ The discrepancies between the findings of this study and those of previous research, especially in terms of clinical experience duration, may be due to the fact that the participants, regardless of their age or years of clinical experience, are considered new and inexperienced in long-term care.

\section{Limitation of the study}

The study was conducted with certain limitations. Firstly, the findings of the study are limited to nurses working in adult long-term care units in Abu Dhabi so the findings might not be conclusive to all nurses working in other emirates. And secondly, only a limited number of participants qualified in the inclusion criteria so findings might not represent all nurses.

\section{Conclusions}

In summary, it is possible to bridge theory to practice gaps and facilitate rapid upskilling of nurses during a pandemic crisis with the use of well-structured learning modules. When faced with a crisis, educators must utilize creative and innovative approaches to address the healthcare professionals' learning needs. The rapid progression of COVID-19 has highlighted the necessity of having proficient and impactful educational and training strategies to improve and enhance skills levels among untrained nurses exposed to long-term care ventilated units with very limited time for training. The delivery of transition modules is one of the many effective methodologies in upskilling nurses with minimal or without prior experience in long-term care settings. Interdisciplinary collaboration, strategic planning, and open communication are crucial factors in the successful development and implementation of education and training during the pandemic crisis.

Based on the findings and conclusions, the author suggests the implementation of a periodic re-evaluation of competency levels with the use of a validated tool to assess the acquisition and retention of necessary competencies after being subjected to the modules. Furthermore, the transition modules may be utilized for newly hired nurses with minimal or without prior experience or exposure to long-term care. Lastly, the author suggests the replication of the study on a larger scale to furnish supplementary evidence reinforcing the effectiveness of utilizing modules in upskilling nurses.

\section{ACKNOWLEDGEMENTS}

The author would like to thank the Management of Amana Healthcare, Senior Director of Clinical Operations for Inpatient Services, Dr. Jason Gray, Director of Clinical Operations, Angela Lewis, and Director of Learning and Development, Hilary Twiggs, for fully supporting this initiative. The author would also like to thank the members of the Education Team, Therapy Team and Respiratory Team for their support in delivering the modules.

\section{CONFlicts of Interest Disclosure}

The author declares no existing potential conflicts of interest in this study and manuscript publication.

\section{REFERENCES}

[1] World Health Organization. Archived: WHO Timeline - COVID19. Who.int. 2020 Apr [accessed 2021 Feb 10]. Available from: https://www. who.int/news/item/27-04-2020-who -timeline---covid-19

[2] Centers for Disease Control and Prevention (CDC). Strategies to mitigate healthcare personnel staffing shortages Cdc.gov. 2020 Dec 14 [accessed 2021 Feb 5]. Available from: https://www.cdc.gov/coronavirus/2019-ncov/hcp/ mitigating-staff-shortages.html

[3] Organization for Economic Cooperation and Development (OECD). Availability of nurses health at a glance: Europe 2020: State of health in the EU cycle OECD iLibrary. 2020 [accessed 2021 Feb 5]. Available from: https ://www. oecd-ilibrary.org/sites/85ef89b8-e $\mathrm{n} /$ index.html?itemId=/content/component/85ef89b8-en
[4] Moulds J. The world needs 6 million more nurses, says the World Health Organization. Weforum.org. 2020 Apr [accessed 2021 Feb 5]. Available from: https : //www . weforum.org/agenda/2020/04/nursing-rep ort-who-nurses-coronavirus-pandemic-health-goals /

[5] International Council of Nurses. International Council of Nurses COVID-19 Update. Icn.ch. 2021 Jan [accessed 2021 Feb 6]. Available from: https://www.icn.ch/sites/default/files /inline-files/ICN\%20COVID19\%20update\%20report\%20F INAL .pdf

[6] Buchan J, Catton H. COVID-19 and the international supply of nurses. Icn.ch. 2020 [accessed 2021 Feb 6]. Available from: https : //www.icn.ch/system/files/documents/2020-07/COVID1 9_internationalsupplyofnurses_Report_FINAL.pdf

[7] Organization for Economic Cooperation and Development (OECD). Workforce and safety in long-term care during the COVID-19 
pandemic. Oecd.org. 2020 Jun [accessed 2021 Feb 6]. Available from: https://www.oecd.org/coronavirus/policy-respo nses/workf orce-and-safety-in-long-term-care-durin g-the-covid-19-pandemic-43f c5d50/

[8] Thompson DC, Barbu MG, Beiu C, et al. The Impact of COVID-19 Pandemic on Long-Term Care Facilities Worldwide: An Overview on International Issues. Biomed Research International. 2020. Available from: https://www.hindawi.com/journals/bmri/2020/887 0249/ PMid:33204723 https://doi.org/10.1155/2020/887 0249

[9] Shinners JS, Africa LA. Rapid validation of clinical competencies in a time of crisis. Nurse leader. 2020. PMid:32837352 https: //doi.org/10.1016/j.mnl.2020.06.012

[10] Gulin Gedik F. Health workforce in the COVID-19 response. Who.int. [accessed $2021 \mathrm{Feb} 11$ ]. Available from: https : //www. wh o.int/docs/default-source/nursing/who-healthworkf orce-in-the-covid-19response. pdf?sfvrsn=62d228b0_2

[11] Almomani E, Sullivan J, Hajjieh M, et al. Simulation-based education programme for upskilling non-critical care nurses for COVID-19 deployment. BMJ simulation \& technology enhanced learning. 2020. https://doi.org/10.1136/bmjstel-2020-000711

[12] Vahedian-Azimi A, Hajiesmaeili M, Kangasniemi M, et al. Effects of stress on critical care nurses: A national cross-sectional study. Journal of Intensive Care Medicine. 2019; 34(4): 311-322. PMid:29277137

[13] Dieckmann P, Torgeirsen K, Qvindesland SA, et al. The use of simulation to prepare and improve responses to infectious disease outbreaks like COVID-19: practical tips and resources from Norway, Denmark, and the UK. Advances in Simulation. 2020 Apr [accessed 2021 Feb 11]. PMid:32308988 https : //doi .org/10.1186/s41077-0 20-00121-5

[14] Amana Healthcare. Long-Term Care. Amanahealthcare.com. [accessed $2021 \mathrm{Feb} 12$ ]. Available from: https: //www . amanahealt hcare.com/en/long-term-care/

[15] Donabedian A. The quality of care: How can it be assessed? JAMA: the Journal of the American Medical Association. 1988; 260(12): 1743. https://doi.org/10.1001/jama.1988.034101200890 33

[16] Botma Y, Labuschagne M. Application of the Donabedian quality assurance approach in developing an educational programmeResearchgate.net. 2017 Sep. Available from: https: //www.researchgate.net/publication/319912392_Appli cation_of_the_Donabedian_quality_assurance_approac h_in_developing_an_educational_programme/figures

[17] Benner P. From Novice to Expert. Virginia.edu. 1982 [accessed 2021 Feb 12]. Available from: https: //www.medicalcenter .virginia.edu/therapy-services/ 3\%20-\%20Benner $\% 20-\% 20$ Novice $\% 20$ to\%20Expert-1.pdf

[18] Thomas CM, Kellgren M. Benner's Novice to Expert Model: An application for simulation facilitators. Nursing Science Quarterly. 2017; 30(3): 227-234. PMid:28899267 https://doi.org/10.1 $177 / 0894318417708410$
[19] Alboliteeh M, Magarey J, Wiechula R. The profile of Saudi nursing workforce: A cross-sectional study. Nursing Research and Practice. 2017; 2017: 1-9. PMid:29214078 https://doi.org/10.1155/ 2017/1710686

[20] Department of Health. Unified healthcare professional qualification requirements. Haad.ae. 2017 [accessed 2021 Feb 12]. Available from: https://www.haad.ae/HAAD/LinkClick.aspx?fileti cket=BaNWzdMghsw\%3d\&tabid=927

[21] Levett-Jones T, Gersbach J, Arthur C, et al. Implementing a clinical competency assessment model that promotes critical reflection and ensures nursing graduates' readiness for professional practice. Nurse Education in Practice. 2011; 11(1): 64-69. PMid:20727825 https://doi.org/10.1016/j.nepr.2010.07.004

[22] Nababan T, Saragih E. Designing Training Module to Improve Nursing Clinical Competence Based on Needs Analysis: A Developmental Study. Scialert.net. 2018 Jun [accessed 2021 Feb 12]. Available from: https://scialert.net/fulltext/?doi=ajsr.2018.3 19. 328 https://doi.org/10.3923/ajsr.2018.319.328

[23] KarimiMoonaghi H, Tohidi S, Shayan A, et al. The effect of selflearning module on nursing students' clinical competency: A pilot study. Iranian Journal of Nursing and Midwifery Research. 2019; 24(2): 91-95. PMid:30820218 https://doi.org/10.4103/ijnm r. IJNMR_46_17

[24] Al-Yateem N, Al-Tamimi M, Brenner M, et al. Nurse-identified patient care and health services research priorities in the United Arab Emirates: a Delphi study. BMC Health Services Research. 2019; 19(1): 77. PMid:30696446 https://doi .org/10.1186/s12913 $-019-3888-5$

[25] Kim MJ, Kim YJ. Variables affecting nursing competency of clinical nurses. Indian journal of science and technology. 2015; 8(26). https://doi.org/10.17485/ijst/2015/v8i26/80758

[26] Lee S, Kim E. The Effects of Korean Medical Service Quality and Satisfaction on Revisit Intention of the United Arab Emirates Government Sponsored Patients. Asian Nurs Res (Korean Soc Nurs Sci). 2017; 11(2): 142-149. PMid:28688500 https://doi.org/10.1 $016 / j$.anr. 2017.05.008

[27] Tariga J. Enhancing Competence in Ventilation Management through Module and Simulation. EC Pulmonol Respir Med. 2020; 9(7): 23 29.

[28] Kiernan L. Evaluating competence and confidence using simulation technology. Nursing (Maarssen). 2018; 48(10): 45-52. PMid:30211760 https://doi.org/10.1097/01. NURSE.00005 45022.36908.f3

[29] Keykha R, Mazlum S, Varasteh S, et al. Clinical competency and its related factors in nurses. International Journal of Pharmacy \& Technology. 2016; 8(3): 8368-18377.

[30] Chan M. Factors Affecting Knowledge, Attitudes, and Skills Levels for Nursing Staff Toward the Clinical Management System in Hong Kong. CIN: Computers, Informatics, Nursing. 2009; 27(1): 57-65. PMid:19060623 https://doi.org/10.1097/NCN . 0b013e3181 8dd3b0 